UM-HSRI-79-52

\title{
EFFECT OF DRIVER'S AGE ON NIGHTTIME LEGIBILITY OF HIGHWAY SIGNS
}

\author{
Michael Sivak \\ Paul L. Olson \\ Leon A. Pastalan
}


Technical Repert Decunentotion Page

\begin{tabular}{|c|c|}
\hline $\begin{array}{l}\text { 1. Roport Mo. } \\
\text { UM-HSRI -79-52 }\end{array}$ & 3. Recipient's Cotalog No. \\
\hline \multirow{3}{*}{$\begin{array}{l}\text { Efirle end Subritle } \\
\text { Legibility of Driver's Age on Nighttime } \\
\text { Legighway Signs }\end{array}$} & 5. Report Dote 1979 \\
\hline & 6. Performing Orgeni zation Code \\
\hline & \multirow{2}{*}{$\begin{array}{l}\text { 8. Porforming Orgenizetion Report No. } \\
\qquad U M-H S R I-79-52\end{array}$} \\
\hline Sivak, M., 01son, P.L. \& Pastalan, L.A. & \\
\hline \multirow{3}{*}{$\begin{array}{l}\text { 9. Porboming Orgenizomion Nemo and Addrass Institute \& } \\
\text { Highway Safety Research Institu of Gerontology } \\
\text { Institute } \\
\text { University of Michigan } \\
\text { Ann Arbor, Michigan } 48109 \\
\end{array}$} & 10. Wort Unit No. (TRAIS) \\
\hline & 11. Contract or Gront No. \\
\hline & \multirow[t]{2}{*}{ 13. Type of Report and Period Covered } \\
\hline \multirow{2}{*}{$\begin{array}{l}\text { 12. Soonsoring Asency Neme and Adress } \\
\text { The National Retired Teachers Association } \\
\text { and the American Association of Retired Persons }\end{array}$} & \\
\hline & 14. Soonsoring Agoney Code \\
\hline
\end{tabular}

15. Supplomontery Notes

16. Abstroet

A field investigation of the effect of driver's age on nighttime legibility of highway signs was performed. Subjects of two age groups (under 25 and over 61 years of age) participated. The results indicate that the legibility distances for the older subjects were $65-77 \%$ of those for the younger subjects with equal high-luminance visual acuity. This finding implies that older drivers are likely to have less distance (and thus less time as well) in which to act on the information transmitted by highway signs. Consequently, it is argued that (1) legibility standards for highway signs should not be based exclusively on data obtained from young observers, and (2) standard (high-luminance) acuity tests have questionable relevance to nighttime visual performance.

\begin{tabular}{|c|c|c|c|c|}
\hline \multicolumn{2}{|c|}{$\begin{array}{l}\text { 17. Koy words } \\
\text { Driving, highway signs, legibility, } \\
\text { age, nighttime, visual acuity, } \\
\text { luminance, luminance contrast }\end{array}$} & \multicolumn{3}{|c|}{ 18. Distribution Statement } \\
\hline $\begin{array}{l}\text { 19. Secourity Closedf. (of this remone) } \\
\text { Unclassified }\end{array}$ & $\begin{array}{r}\text { 20. Soavity Cless } \\
\text { UnCl }\end{array}$ & $\begin{array}{l}\text { if. (of this onege) } \\
\text { assified }\end{array}$ & $\begin{array}{l}\text { 21. No. of Poges } \\
15\end{array}$ & 22. Price \\
\hline
\end{tabular}


TABLE OF CONTENTS

ACKNOWLEDGEMENTS ..................... i

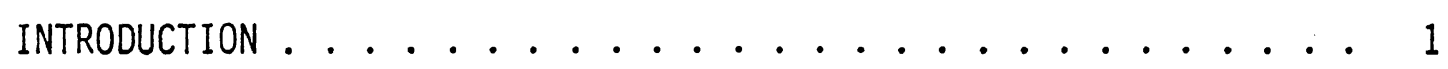

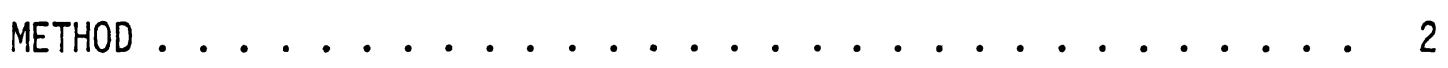

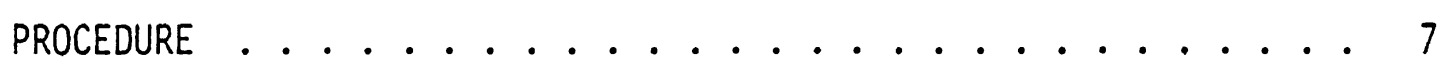

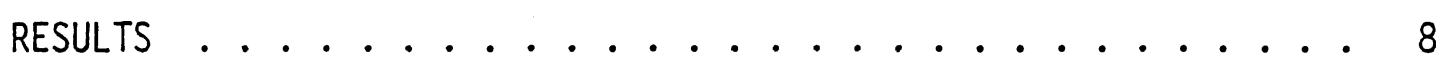

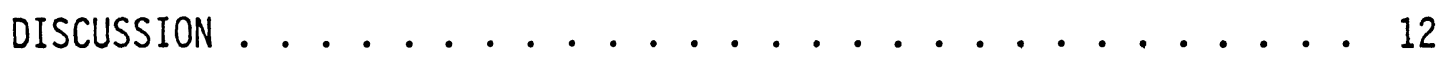

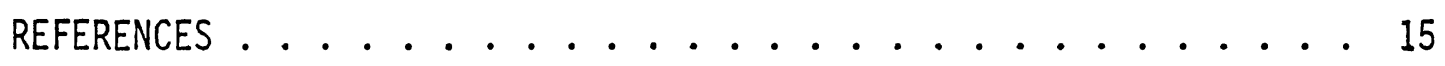




\section{ACKNOWLEDGEMENTS}

This research was supported by a grant from the National Retired Teachers Association and the American Association of Retired Persons.

We wish to thank Anna R. Herzog, Richard J. Kaplan, and Daniel J. Weintraub for their constructive criticism of an earlier draft of this paper. 
In a recent laboratory study, 01 son and Bernstein (1977) estimated nighttime sign legibility by means of a Landolt rings task. A range of stimulus characteristics was employed as independent variables, including legend (Landolt ring) luminance, background luminance (and thereby legend/background contrast ratio), and legend size. The dependent variable was the percent correct identification of the orientation of the gap. Small samples of younger and older subjects (under 33 and over 66 years of age) participated. The two groups were matched on high-luminance far acuity. The results showed the older group to be performing substantially worse than the younger group under all tested conditions. Specifically, the results indicate that, for approximately equal performance the size of the Landolt ring had to be 1.5 times larger for the older than for the younger group. These findings suggest that in an actual driving situation it is likely that the older driver has to come closer to a traffic sign to be able to read it. Consequently, the older driver is likely to have less distance (and thus less time) in which to act on the information contained in the sign.

Since the implication of these results are substantial, it was thought desirable to investigate legibility performance under conditions approximating actual driving situations. Furthermore, it was felt important to determine whether the sizable age differences found by 01 son and Bernstein (1977) will hold across a wide range of currently utilized sign materials. 
METHOD

This was a nighttime field investigation in which subjects either drove or rode in an automobile and at the same time watched for a small retroreflective sign which had been erected along the right side of the road showing either a left-or right-facing $E$. The measure of performance was the distance at which the subjects could identify the orientation of the letter ( $\exists$ or E).

Subjects

Subjects of two age levels participated. The younger subjects were between 18 and 24 years old while the older subjects were between 62 and 74 years old. Fifty potential subjects were screened with a Titmus Vision Tester using a color vision test, a high luminance $\left(80.5 \mathrm{~cd} / \mathrm{m}^{2}\right)$ far acuity test, and a low luminance $\left(2.3 \mathrm{~cd} / \mathrm{m}^{2}\right)$ far acuity test. Twelve older and twelve younger persons whose scores could be most closely matched on high-luminance far acuity were selected to participate. All subjects had normal color vision. Tables 1 and 2 list the subjects and their visual characteristics. Test Signs

The test signs were $90 \mathrm{~cm}$ high and $90 \mathrm{~cm}$ wide. They were constructed by attaching retroreflective sheeting to aluminum panels. The nonreflectorized (black) unit had a porcelain enamel finish and was supplied by a manufacturer of such signs. A plastic ledge was attached to each background to support a $25.4 \mathrm{~cm}$ tall letter target. The entire sign was supported on a flat black panel. With this 
TABLE 1. Characteristics of Younger Subjects

\begin{tabular}{|c|c|c|c|c|}
\hline \multirow[b]{2}{*}{ Age } & \multirow[b]{2}{*}{ Sex } & \multicolumn{2}{|c|}{ Far Acuity } & \multirow[b]{2}{*}{ Glasses? } \\
\hline & & $\begin{array}{l}\text { At High } \\
\text { Luminance Level } \\
\left(80.5 \mathrm{~cd} / \mathrm{m}^{2}\right) \\
\end{array}$ & $\begin{array}{c}\text { At Low } \\
\text { Luminance Leve 1 } \\
\left(2.3 \mathrm{~cd} / \mathrm{m}^{2}\right) \\
\end{array}$ & \\
\hline 24 & M & $20 / 17$ & $20 / 22$ & No \\
\hline 24 & $F$ & $20 / 25$ & $20 / 25$ & No \\
\hline 24 & M & $20 / 20$ & $20 / 22$ & No \\
\hline 18 & M & $20 / 18$ & $20 / 22$ & Yes \\
\hline 20 & $F$ & $20 / 15$ & $20 / 30$ & No \\
\hline 19 & $\mathrm{~F}$ & $20 / 22$ & $20 / 40$ & Yes \\
\hline 18 & M & $20 / 17$ & $20 / 17$ & No \\
\hline 22 & $\mathrm{~F}$ & $20 / 18$ & $20 / 25$ & No \\
\hline 20 & M & $20 / 17$ & $20 / 22$ & No \\
\hline 19 & $F$ & $20 / 17$ & $20 / 40$ & Yes \\
\hline 18 & $F$ & $20 / 17$ & $20 / 25$ & No \\
\hline \multirow[t]{2}{*}{18} & M & $20 / 17$ & $20 / 25$ & Yes \\
\hline & Mean & $20 / 18.3$ & $20 / 26.5$ & \\
\hline
\end{tabular}


TABLE 2. Characteristic of 01 der Subjects

\begin{tabular}{|c|c|c|c|c|}
\hline \multirow[b]{2}{*}{ Age } & \multirow[b]{2}{*}{ Sex } & \multicolumn{2}{|c|}{ Far Acuity } & \multirow[b]{2}{*}{ Glasses? } \\
\hline & & $\begin{array}{l}\text { At High } \\
\text { Luminance Level } \\
\left(80.5 \mathrm{~cd} / \mathrm{m}^{2}\right) \\
\end{array}$ & $\begin{array}{c}\text { At Low } \\
\text { Luminance Leve1 } \\
\left(2.3 \mathrm{~cd} / \mathrm{m}^{2}\right)\end{array}$ & \\
\hline 68 & M & $20 / 18$ & $20 / 35$ & Yes \\
\hline 70 & $F$ & $20 / 22$ & $20 / 70$ & Yes \\
\hline 70 & M & $20 / 20$ & $20 / 40$ & Yes \\
\hline 62 & M & $20 / 17$ & $20 / 30$ & Yes \\
\hline 70 & $F$ & $20 / 15$ & $20 / 35$ & Yes \\
\hline 72 & $F$ & $20 / 17$ & $20 / 100$ & Yes \\
\hline 74 & $F$ & $20 / 18$ & $20 / 40$ & Yes \\
\hline 66 & M & $20 / 18$ & $20 / 15$ & Yes \\
\hline 69 & M & $20 / 18$ & $20 / 40$ & Yes \\
\hline 76 & M & $20 / 22$ & $20 / 35$ & Yes \\
\hline 74 & $F$ & $20 / 17$ & $20 / 17$ & Yes \\
\hline \multirow[t]{2}{*}{70} & $F$ & $20 / 22$ & $20 / 50$ & Yes \\
\hline & Mean & $20 / 18.7$ & $20 / 43.5$ & \\
\hline
\end{tabular}


arrangement the letter was about $1.4 \mathrm{~m}$ above the pavement. The support was placed on the edge of the paved surface of the test road. Color of the Background and of the Legend. The following seven standard highway sign colors were used for the background of the sign: green, red, blue, black (a nonreflective green, which appeared black under the test conditions), white, orange, and yellow. A white legend was used with the first four background colors, a black legend with the last three. (The legend consisted of the single capital letter "E" referred to above.) Two different materials were used for white legends. One was a metal letter studded with highly retroreflective buttons, the other was faced with a low-retroreflective sheeting. The black legend was made of a plastic sheeting.

Photometric Properties. The specific luminance of the lowretroreflective letter was $86 \mathrm{~cd} / 1 \mathrm{x} / \mathrm{m}^{2}$ (at $0.2^{0}$ and $-4^{0}$ ) while that of the button letter was approximately $600 \mathrm{~cd} / 1 \mathrm{x} / \mathrm{m}^{2}$. The specific luminance of the background materials are listed in Table 3 , which also contains the luminance contrast ratios provided by the two white legends and the corresponding backgrounds, (Since the specific luminance of the black letter used approaches zero, contrast ratios for the black legend on white, yellow, or orange backgrounds could not be evaluated.)

As can be seen from Table 3, color and contrast are confounded. Since the materials used represent a sample of currently available materials, it was impossible to vary color and specific luminance (and consequently contrast) independently. 
TABLE 3. Background Specific Luminances and Contrast Ratios Provided by the Legend and the Background

\begin{tabular}{|c|c|c|c|}
\hline \multirow[b]{2}{*}{$\begin{array}{l}\text { Color of the } \\
\text { Background }\end{array}$} & \multirow{2}{*}{$\begin{array}{l}\text { Background Specific Luminance } \\
\left(\mathrm{cd} / 1 \times / \mathrm{m}^{2} \text { at } 0.2^{0} \&-4^{0}\right)\end{array}$} & \multicolumn{2}{|c|}{ Contrast Ratio } \\
\hline & & $\begin{array}{l}\text { Sheeting } \\
\text { Letter }\end{array}$ & $\begin{array}{l}\text { Button } \\
\text { Letter }\end{array}$ \\
\hline Red & 58 & $1.5: 1$ & $10.3: 1$ \\
\hline Green & 38 & $2.3: 1$ & $15.8: 1$ \\
\hline Blue & 12 & $7.2: 1$ & $50.0: 1$ \\
\hline Black & 0.06 & $1,433: 1$ & $10,000: 1$ \\
\hline White & 286 & - & -- \\
\hline Yellow & 190 & - & -- \\
\hline Orange & 79 & - & -- \\
\hline
\end{tabular}




\section{Facility}

The test was conducted on a dark, unused dead-end road. The road has two lanes, is $800 \mathrm{~m}$ long, and is flat and straight.

For the actual test, two signs were set up, facing in opposite directions, $400 \mathrm{~m}$ away from the ends of the road. Each run started with the subject vehicle at one end of the road. The driver proceeded in the right lane (at a speed of approximately $24 \mathrm{~km} / \mathrm{hour}$ ) passing the test sign to his or her right, then continued to the end of the road, turned around, and started the next run.

\section{Test Vehicle}

The test vehicle was a standard full-size station wagon. The vehicle has a distance measuring system with a digital readout in feet accurate to $0.1 \%$. This readout was videotaped along with the code for the actual orientation of the letter $E$.

\section{PROCEDURE}

The data were collected from three subjects at a time (a driver and two passengers). All three subjects were seated in the front seat of the car. (From each age group a total of four subjects participated as drivers and eight as riders.) Each subject held a push button switch. When pressed, each switch turned on a small light bulb in the rear compartment of the vehicle. The switches operated silently and thus subjects were unaware of the timing of each other's responses. The experimenter, who sat in the second seat behind the subjects, also had a switch which turned on a fourth 
bulb. The experimenter pressed his switch when he was passing the sign. This array of bulbs was viewed by a camera and videotaped simultaneously with the distance readout. For each run then, three lights indicated when each subject had identified the orientation of the letter and the last light marked the position of the sign. By subtracting the first three distance readings (corresponding to the onset of the lights) from the last, legibility distances could be determined.

The instructions specified that the subjects were to press the button once for a left orientation of the letter and twice for a right orientation. The importance of responding only when quite sure of the letter's orientation was stressed. After the instructions had been read, all questions were answered and two practice runs given. The 44 experimental trials (four replications per each background/legend combination) took about 1 1/4 hours to complete. A short break was allowed twice during the sequence. Any required make-up trials were taken at the end of the regular sequence.

The order in which the sign variables were presented was varied systematically to compensate for order effects. The orientation of the letter "E" was varied randomly. A11 data were taken using standard low beams.

\section{RESULTS}

There were only five incorrect responses out of the total of 1,056 trials $(0.5 \%)$. In these cases the distance at which the second 
(corrected) responses was made was taken to be the legibility distance. The mean legibility distances for each background/legend combination are presented in Figure 1. (Since the legibility distances were not affected by the subject's position in the car, the legibility distances were combined across the positions.) As can be seen from Figure 1, the legibility distances for all combinations of the background and the legend are consistently shorter for the older subjects than for the young. In other words, the older subjects had to get closer to the sign in order to identify the orientation of the letter $E$. For the older subjects the mean legibility distances in the various conditions were $65-77 \%$ of those for the younger subjects. Correlation coefficients between low-luminance acuity and mean legibility distance for all conditions were computed across all subjects and also within each age group separately. (A significant negative correlation would indicate a relationship between good acuity and long legibility distance.) The obtained coefficients are -0.28 across all subjects, +0.01 for the older subjects, and +0.04 for younger subjects. The corresponding correlation coefficients between high-luminance and mean legibility distance are -0.02 across a11 subjects, -0.47 for the 01 der subjects, and t0.30 for the younger subjects. None of the coefficients are significantly different from zero $(p>0.05)$.

Figure 2 shows the relation between the contrast of the legend/background combinations and the legibility distances obtained in the eight conditions where the contrast could be evaluated. The 


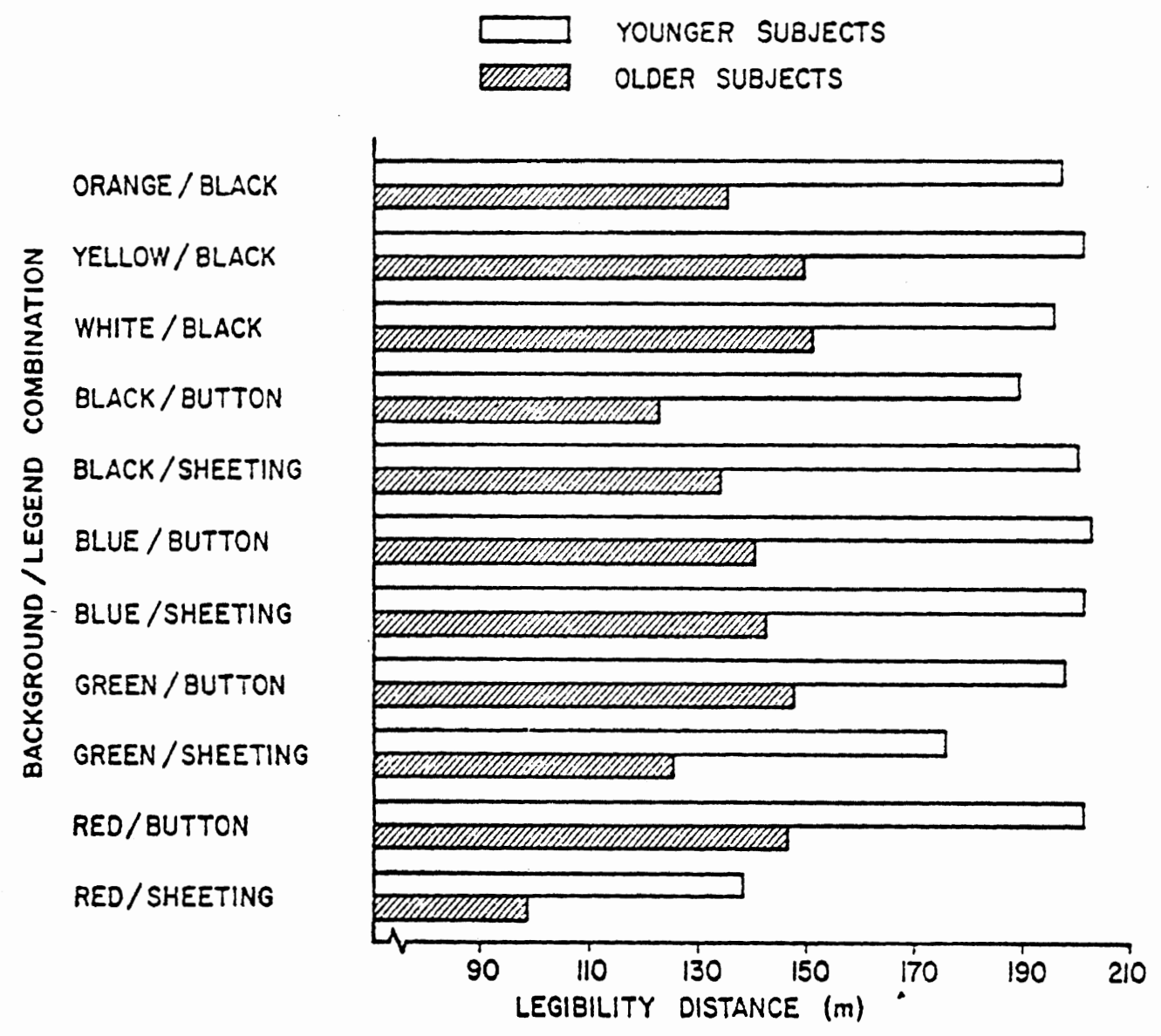

Figure 1. Legibility distance as a function of background/legend combination and age. Sheeting and button refer to the two types of white letters used. 


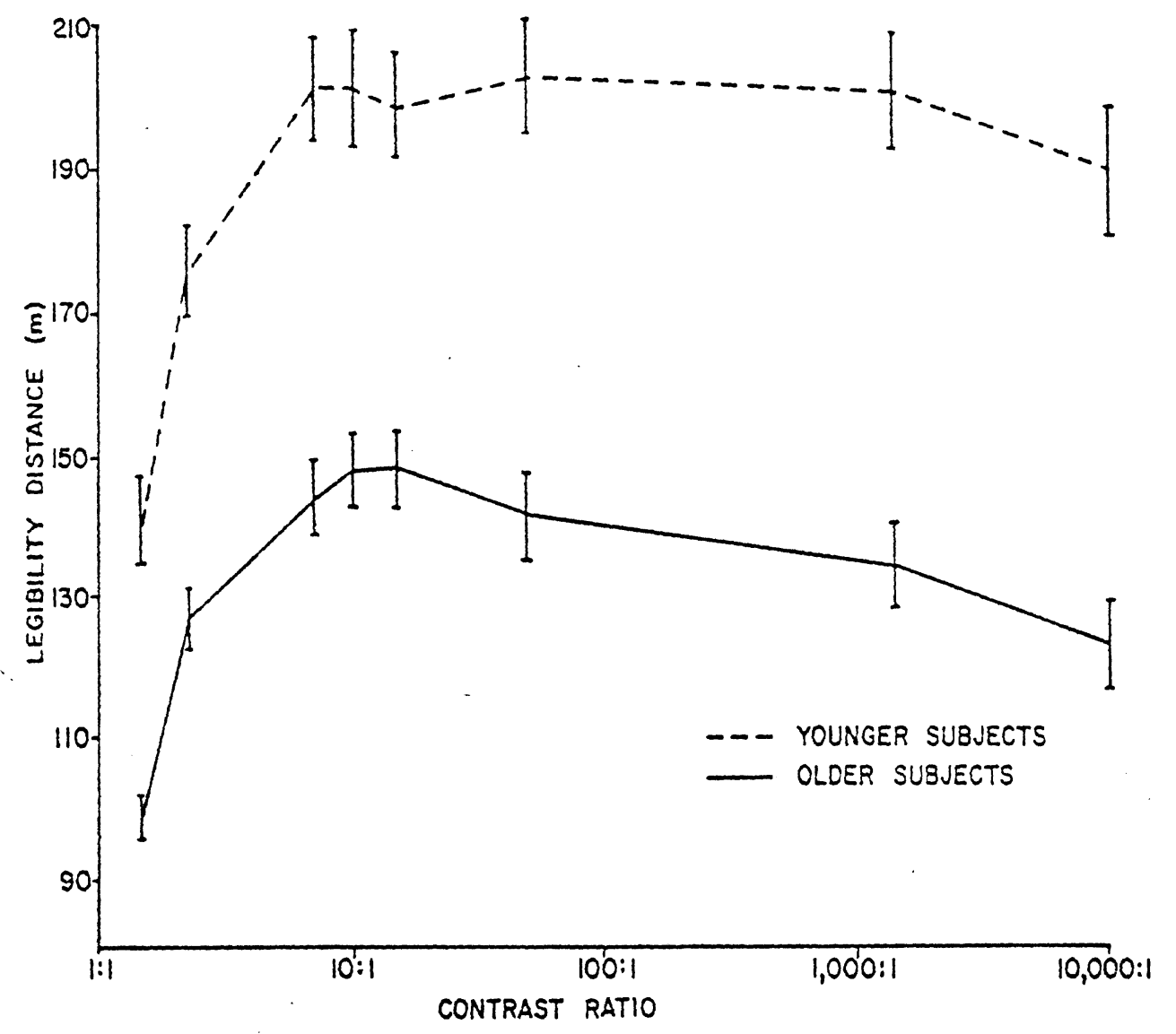

Figure 2. Legibility distance as a function of luminance contrast and age. The vertical bars represent \pm 1 standard error of each mean. 
curves for both the younger and the older subjects tend to asymptote at a contrast ratio of about 10:1.

\section{DISCUSSION}

The major conclusion from the present study is that older subjects perform substantially worse than younger subjects on a nighttime legibility task using a wide range of currently available sign materials. This finding confirms the laboratory results of 01son and Bernstein (1977). An important implication of this finding is that at night the older driver has less time available in which to act on the information contained in highway signs.

The results of the present study do not allow a positive identification of the characteristics of older people causing their poorer performance. It is obvious that high-luminance acuity does not account for the obtained age-related differences, since 1) having the two age groups matched on the high-luminance acuity did not result in equal nighttime legibility performance, and 2) there was no significant correlation between high-luminance acuity and legibility distance. It will be noted from inspection of Tables 1 and 2 that there were substantial differences between the age groups on low-luminance acuity and it could be hypothesized that this difference is responsible, at least in part, for the obtained effect of age on legibility distance. However, the absence of significant correlation between low-luminance acuity and legibility distance does not support this hypothesis. Another factor which 
could possibly contribute to the shorter legibility distances for the older people is the increased reluctance of the elderly to commit themselves unless they feel they have sufficient information for a correct decision (e.g., Botwinick, 1973). However, the likelihood of this explanation is lessened by the results of 01 son and Bernstein (1977). Although in their study a forced-choice procedure was used (thereby controlling for willingness to commit oneself), the older subjects' legibility performance was still below that of the younger subjects. Another hypothes is is that the age-related decrements in decision and response speeds (e.g., Welford, 1977) are responsible for the legibility differences. However, the speed decrements are not of sufficiently large magnitudes to account fully for the legibility distance differences.

Several recent studies (e.g., Hind, Tritt, and Hoffmann, 1977; 01son and Bernstein, 1977) have shown that legibility is an inverse $U$-shaped function of the legend/background luminance ratio, implying that intermediate levels of contrast are optimal. It is tempting to interpret Figure 3 of the present study as supporting these findings. However, since the present study was not designed to investigate the relation between contrast and legibility, contrast levels remained confounded with colors and luminance levels. (Similarly, no conclusions about the effect of color on the legibility of signs can be safely made.)

There are two major practical implications of the present study. First, reliance on legibility estimates of young observers for establishing sign standards is likely to be insufficient in providing 
adequate legibility for older drivers. Consequently, legibility standards should not be based exclusively on the data obtained from young observers. Second, the present findings raise serious questions about the relevance of standard (high-luminance) acuity tests to nighttime legibility performance. 


\section{REFERENCES}

Botwinick, J. Aging and Behavior. New York: Springer, 1973. Hint, P.R., Tritt, B.H., and Hoffman, E.R. Effects of Level of Illumination, Strokewidth, Visual Angle and Contrast on the Legibility of Numerals of Various Fonts. Australian Road Research Board Proceedings, 1976, 8, 59-85.

01son, P.L., and Bernstein, A. Determine the Luminance Requirements of Retroreflective Highway Signing. NCHRP Project 3-24. The University of Michigan, Highway Safety Research Institute, Report No. UM-HSRI-77-6.

Welford, A.T. Motor performance. In J.E. Birren and K.W. Schaie (Eds.), Handbook of the Psychology of Aging, New York: Van Nostrand Reinhold, 1977. 
